\title{
Prevalence and Pattern of Potential Drug-Drug Interactions in the Critical Care Units of a Tertiary Hospital in Alexandria, Egypt
}

\section{Sarah Mahmoud Abd El Samia Mohamed ${ }^{1}$, Zahira Metwaly Gad ${ }^{2}$, Nessrin Ahmed El-Nimr ${ }^{3 *}$ and Ahmed Abdel Hady Abdel Razek ${ }^{4}$}

${ }^{1}$ Pharmacist, Alexandria Main University Hospital, Egypt

${ }^{2}$ Professor of Epidemiology, Epidemiology Department, High Institute of Public Health, Alexandria University, Egypt

${ }^{3}$ Lecturer of Epidemiology, Epidemiology Department, High Institute of Public Health, Alexandria University, Egypt

${ }^{4}$ Lecturer of Critical Medicine, Faculty of Medicine, Alexandria University, Egypt

\begin{abstract}
Background: The complexity of the pharmacotherapy involved in the simultaneous use of several drugs and various therapeutic classes makes critically ill patients at an increased risk for potential DDIs. The objectives were to estimate the prevalence of potential DDIs in the critical care units (CCUs) at a main trtiary hospital, to analyze their clinical significance, onset, documentation and severity and to identify their possible determinants.

Materials and methods: Using a cross sectional design, 750 patients, admitted to the CCUs, whose medical prescriptions contain 4 or more drugs were included. A pre-designed structured questionnaire and a record review sheet were used to collect the following data: sociodemographic, smoking habits, medical history, long term used medications, the presence of hospital aquired infections, APAHE II score, length of stay, organ impairment, number of drugs per prescription and the number of prescribing physicians. Calculating the number of interactions for each patient was performed. The list of prescribed drugs for patient was analyzed using different software.

Results: The prevalence of potential DDIs among patients admitted to CCUs was $53.07 \%$. The mean number of interactions occurred per patient was $2.98 \pm 1.91$. The highest proportion of interactions had a significance number 1.0 , possible and suspected documentation, delayed onset and moderate severity. Age of the patient and the number of prescribed drugs were the two independent factors found to be significantly affecting the prevalence of potential DDIs.

Conclusion: Critically ill patients are at risk of DDIs and the patients' age and the number of drugs prescribed increases this possibility.
\end{abstract}

Keywords: Critical care; Drug-drug interaction

\section{Introduction}

A drug-drug interaction (DDI) may be defined as the pharmacologic or clinical response to the administration of a drug combination different from that anticipated from the known effects of the two agents when given alone [1]. Stockley's drug interaction definition declares that an interaction is said to occur when the effects of one drug are changed by the presence of another drug, food, drink or by some environmental or chemical agent $[2,3]$. The clinical result of a DDI may manifest as antagonism, synergism or idiosyncratic. According to Drug Interaction Facts, each drug interaction pair has a monograph that includes the following sections: significance, type, mechanism, effect, management and monitoring of each DDI [3].

Drug-drug interactions are a preventable cause of morbidity and mortality $[4,5]$. Previous studies showed that DDIs significantly increased risk of hospitalization, significantly prolonged length of hospital stay, cost of treatment and elevated the risk of death [68]. The incidence and degree of severity of an interaction depend on both patient-related factors and information about the effects of the interaction. Patient-related factors include age, genetics, disease process, impairment of organ function, diet, alcohol consumption and smoking $[1,9,10]$. One of the risk factors for the occurrence of DDIs is the number of prescribed drugs. A positive correlation between polypharmacy and DDIs have been demonstrated in several studies $[9,10]$. The risk of DDIs can increase from approximately $6 \%$ in patients taking only two medications to $50 \%$ in those taking five medications and $100 \%$ in those taking ten medications [11]. Other determinants for the occurrence of a DDI include the pharmacokinetic profile and the pharmacological characteristics of the medications [4].
Critical care medicine is a multidisciplinary subspecialty that has realized remarkable growth over the last 40 to 50 years, paralleling advances in life support technologies [12]. Common features among the majority of critically ill patients are their acuity, complex pathophysiologic states and the use of a large number of pharmacologic agents in their management. On average, these patients have six to nine drugs prescribed per day while being cared for in the critical care unit (CCU) $[12,13]$. Due to the complexity of the pharmacotherapy involved in the simultaneous use of several drugs and various therapeutic classes, critically ill patients are at an increased risk for DDIs [4].

Recognition of the drug therapy selection, dosing and monitoring demands within the CCU by pioneering clinical pharmacists caused the development of critical care as a specialty within the pharmacy profession $[12,13]$. The number of adverse drug events and the subsequent cost of these events can be reduced by pharmacist intervention. Monitoring for adverse drug reactions was an importance

*Corresponding author: Nessrin Ahmed El-Nimr, Lecturer of Epidemiology, Epidemiology Department, High Institute of Public Health, Alexandria University Egypt, Tel: (+2)01005051138; E-mail: dr.elnimr@gmail.com

Received November 12, 2013; Accepted December 22, 2013; Published December 24, 2013

Citation: El Samia Mohamed SMA, Gad ZM, El-Nimr NA, Abdel Razek AAH (2013) Prevalence and Pattern of Potential Drug-Drug Interactions in the Critical Care Units of a Tertiary Hospital in Alexandria, Egypt. Adv Pharmacoepidemiol Drug Saf 2: 144. doi:10.4172/2167-1052.1000144

Copyright: () 2013 El Samia Mohamed SMA, et al. This is an open-access article distributed under the terms of the Creative Commons Attribution License, which permits unrestricted use, distribution, and reproduction in any medium, provided the original author and source are credited. 
responsibility of the pharmacist. Many medications taken by CCU patients have significant adverse effect profiles and multiple known drug drug interactions [13].

The prevalence of potential DDIs among critically ill patients was studied by many authors in different countries [4,5,14-17]. In a study conducted to assess the role of pharmacist in identification of medication related problems in the ICU of a teaching hospital in Egypt, potential DDIs were detected among $8.4 \%$ of patients [18]. To our knowledge, no studies have been conducted in this field in our city. The objectives of the present study were to estimate the prevalence of potential DDIs in the CCUs at a main trtiary hospital in Alexandria Egypt, to analyze their clinical significance, onset, documentation and severity and finally to identify their possible determinants.

\section{Materials and Methods}

A cross-sectional study was conducted throughout the second half of 2011 in the $1^{\text {st }}$ and $3^{\text {rd }}$ Critical Care Units (CCUs) at a main tertiary hospital in Alexandria, Egypt. The study was approved by the ethics committee at the High Institute of Public Health, Alexandria University. In addition, an approval to conduct the study was obtained from the hospital director and the head of the critical care department.

The inclusion criteria included patients (all ages and both sexes) admitted to the CCUs whose medical prescriptions contain 4 or more drugs. Patients using topical drugs (ointments, creams, ear drops or eye drops) were not included. The sample size was calculated using Epi info 6 program. Based on a prevalence of potential DDI of 8.4\%, [19] level of significance $95 \%$ and level of precision $2 \%$, the minimum required sample size was 750 patients. Patients were consecutively included in the study from both units till the completion of the sample size.

The required data were collected by interviewing patients (if conscious) or one of their relatives (during the official times for the visit) using a pre-designed structured questionnaire. The collected data included socio-demographic characteristics as age, sex, marital status, education and occupation as well as the social habitual risk factors as smoking cigarettes and shisha (local waterpipe).

A record review sheet was prepared to collect data about the presence of co-morbidities, the long-term used medications, the presence of hospital acquired infections, Acute Physiology and Chronic Health Evaluation II score (APACHE II score), length of stay in the CCUs, renal and hepatic impairments. In addition, a 24 hours prescription was reviewed for each patient $[15,16]$. Information regarding the number of drugs per prescription and the number of prescribing physicians during the patient's stay at the CCUs were also obtained.

Calculating the number of interactions between the prescribed drugs for each patient was performed. A to Z Drug Facts was used for classification of drug groups [20]. The list of drugs for each prescription was analyzed using each of the following: Drug interaction checker software "Drug Interaction Facts" (iFacts-AZ) Version: 13.5.0/2010.5.28, [21]. Stockley's Drug Interactions [2] and the British National Formulary [22]. Free online drug interaction checker programs were also used to identify the clinical value (level of significance), documentation (level of evidence or records), onset of effect (rapid or delayed) and the severity of the interaction (minor, moderate or major) [23-26].

\section{Data management}

The collected data were coded, entered and cleaned using SPSS for Windows version 16.0 (SPSS Inc., Chicago, IL, USA). Descriptive statistics using frequency distribution tables and graphs was carried out. For quantitative variables, mean and standard deviation were calculated, while percent was used to describe categorical data. Pearson's chi square was used for analysis of categorical data. Multiple logistic regression analysis was used to estimate the strength of association between the exposure and a binary outcome. All statistical analyses were done using two tailed tests and a $p$ value $<0.05$ was considered to be statistically significant.

\section{Results}

From a total of 750 patients studied, with the mean age of 44.46 \pm 21.29 years, $54.8 \%$ were males, $69.62 \%$ were married and $34.17 \%$ were illiterate. The mean length of stay was $9.02 \pm 12.70$ days, the mean number of prescribed drugs per patient was $7 \pm 2$ and the mean number of prescribing physicians was $3 \pm 2$ for each patient. The principle conditions for admission of patients to the CCUs included cardiovascular diseases (44.53\%), respiratory diseases (19.6\%), external causes for morbidity and mortality such as: road traffic accidents, near drowning, gun shooting and explosion injury (14.13\%) and injuries and poisoning (12.13\%). About $62 \%$ of patients had co-morbid conditions including cardiovascular diseases (46.46\%), endocrinal and metabolic diseases $(26.25 \%)$, respiratory and genitourinary diseases $(6.97 \%$ and $6.16 \%$ respectively).

The prevalence of potential DDIs among patients admitted to CCUs was $53.07 \%$, figure 1 . The majority of patients $(67.34 \%)$ had 1-3 interactions among their medications, while $28.39 \%$ had $4-6$ interactions. Only $4.27 \%$ of patients had 7 or more 1 potential DDIs among their prescribed medications. The mean number of interactions occurred per patient was $2.98 \pm 1.91$ interactions (range, 1-12 interactions). There were 89 different potential DDI pairs. The total number of potential DDIs was 1183 interactions.

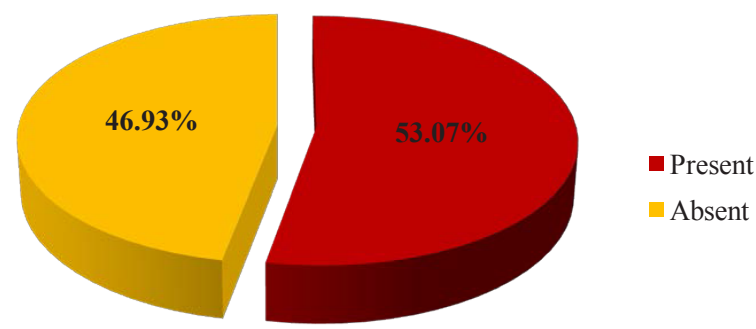

Figure 1: Prevalence of potential DDIs among patients admitted to CCUs (Alexandria, 2011).

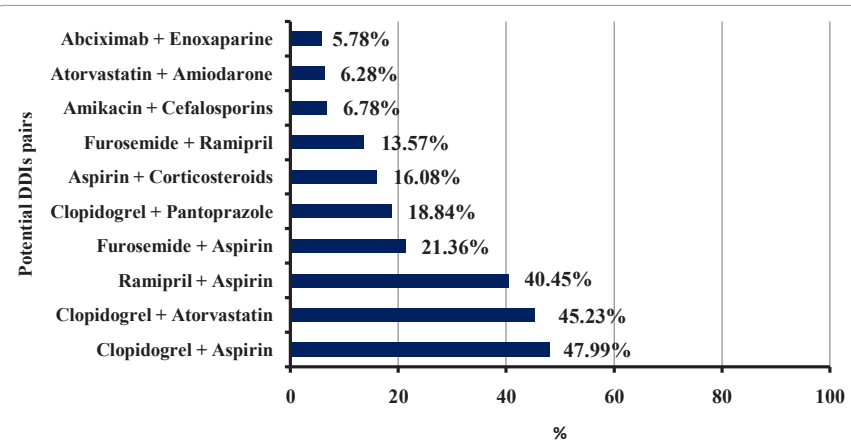

Figure 2: Top 10 potential DDls among patients admitted to the CCUs (Alexandria, 2011) 
Figure 2 illustrates the top ten potential DDIs that occurred among patients admitted to the CCUs. Interactions from the co-administration of Clopidogrel with Aspirin ranked first (47.99\%), followed by the co-administration of Clopidogrel with Atorvastatin (45.23\%) and the co-administration of Ramipril with Aspirin (40.45\%). The proportion of interactions that resulted from the co-administration of Furosemide with Aspirin, Clopidogrel with Pantoprazole, Aspirin with Corticosteroids and Furosemide with Ramipril ranged from $13.57 \%$ to $21.36 \%$, while $5.78 \%$ to $6.78 \%$ of patients had interactions that resulted from the co-administration of Amikacin with Cephalosporins, Atorvastatin with Amiodarone, and the co-administration of Abciximab with Enoxaparine.

Figure 3 shows the distribution of the detected 1183 potential DDIs according to their clinical value, documentation, onset and severity. As regards the clinical value (Figure $3 \mathrm{a}$ ), the highest proportion of interactions $(30.52 \%)$ had a significance number 1.0 , followed by significant numbers 4.0 and 2.0 (27.13\% and $25.71 \%$, respectively). The highest proportion of interactions had possible and suspected documentation, followed by probable documentation $(35.76 \%, 31.87 \%$ and $26.63 \%$, respectively). Interactions with unlikely documentations were the least common (1.52\%), as shown in figure $3 \mathrm{~b}$. Regarding onset of effect (Figure 3c), $77.09 \%$ of the potential DDIs detected had a delayed onset (after 24 hours) and $18.85 \%$ had a rapid onset (within the 24 hours). Considering severity, nearly half of the interactions $(52.83 \%)$ had moderate effects (worsening of the clinical condition) and $32.21 \%$ had major effects (potential risk of life or irreversible damage). Only $14.96 \%$ had minor effects (imperceptible or light), figure $3 \mathrm{~d}$.

Table 1 shows that of the age of patients admitted to the CCUs ranged between 9 months to 99 years. It is obvious from the table that as the age of patients increased, the prevalence of potential DDIs increased. This association was statistically significant $\left(\mathrm{X}^{2}=100.1\right.$, $p=0.000)$. Males had a slightly higher prevalence of potential DDIs than females. However, this difference was not statistically significant. Married and widowed patients had higher rates of potential DDIs, while single patients had the least rate of potential DDIs. This association was statistically significant $\left(\mathrm{X}^{2}=52.6, p=0.000\right)$. It is clear from the table that the higher the level of education, the lower the proportion of potential DDIs. This association was statistically significant $\left(\mathrm{X}^{2}=35.9, p=0.000\right)$. Patients who were retired, housewives or non skilled workers had higher rates of potential DDIs, followed by skilled workers. Students had the least proportion of potential DDIs. This association was statistically significant $\left(\mathrm{X}^{2}=41.9, p=0.000\right)$. As regards smoking habits, higher rates of potential DDIs were found among patients who smoked cigarettes and shisha, compared to those who did not smoke. The association between smoking and the presence of potential DDIs was statistically significant $\left(\mathrm{X}^{2}=11.1, p=0.000\right.$ and $\mathrm{X}^{2}=28.3, p=0.001$, respectively).

Table 2 shows that the mean length of stay of patients at the CCUs was $9.02 \pm 12.7$ days (range, 1-125 days). Patients who stayed in the CCUs between 25 to $<30$ days had the highest prevalence of potential DDIs, followed by those who stayed from 5 to $<10$ days, while those who stayed for 30 days or more had the lowest proportion of potential DDIs, with a statistically insignificant difference. Patients who had renal or hepatic impairments had a higher prevalence of potential DDIs. This association was statistically significant $\left(\mathrm{X}^{2}=5.1, p=0.024\right)$. The table also shows that the mean APACHE II score of patients admitted to CCUs was $18 \pm 10$ (range, 2-45). The highest prevalence of potential DDIs was found among patients who had an APACHE II score that ranged from 31 to $<41$, followed by those who had a score that ranged from 11 to $<21$. The least prevalence was found among patients with a score range of 41 to 51 . This association was statistically significant $\left(\mathrm{X}^{2}=13.4\right.$, $p=0.010)$.
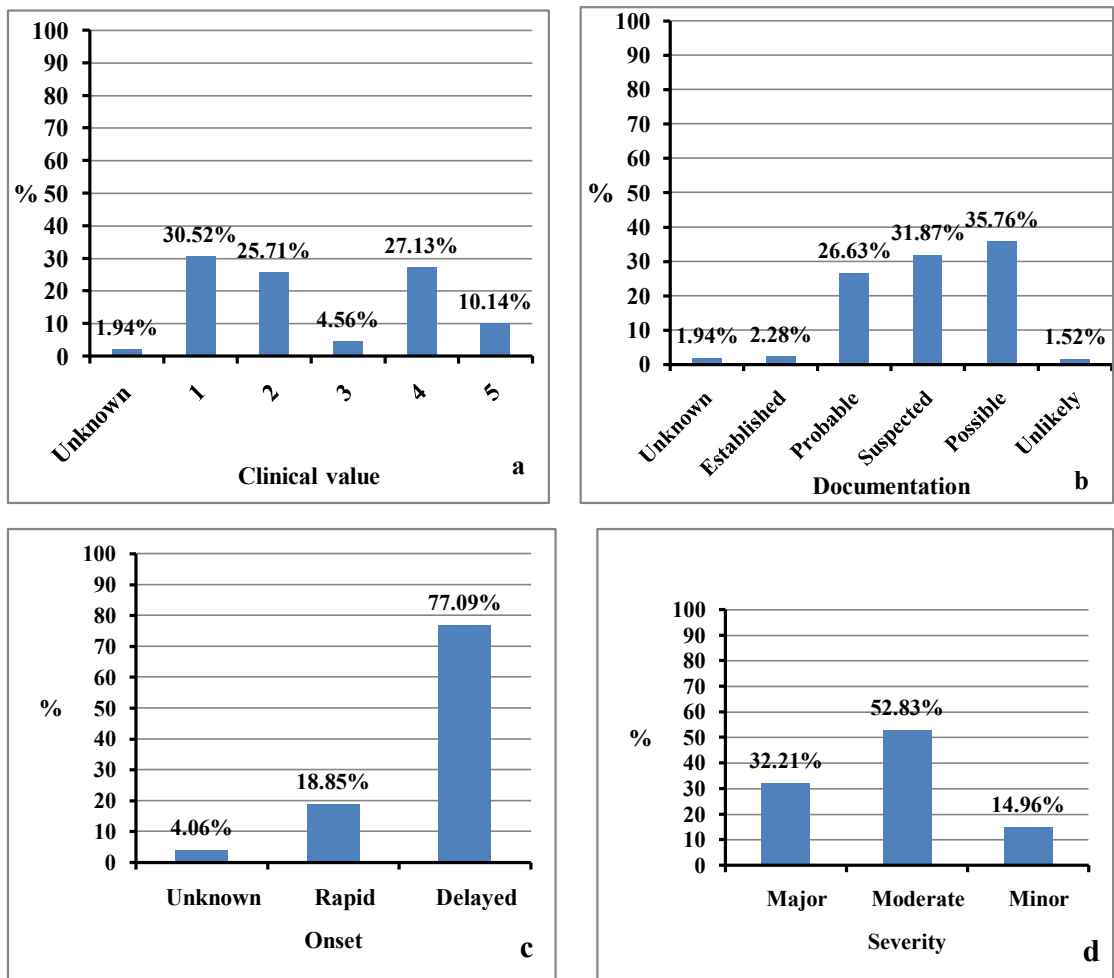

Figure 3: Distribution of potential DDIs among medications prescribed to patients admitted to CCUs according to the a) clinical value, b) documentation, c) onset and d) severity of the interactions (Alexandria, 2011). 
Citation: El Samia Mohamed SMA, Gad ZM, El-Nimr NA, Abdel Razek AAH (2013) Prevalence and Pattern of Potential Drug-Drug Interactions in the Critical Care Units of a Tertiary Hospital in Alexandria, Egypt. Adv Pharmacoepidemiol Drug Saf 2: 144. doi:10.4172/2167-1052.1000144

Page 4 of 6

\begin{tabular}{|c|c|c|c|}
\hline \multirow{3}{*}{$\begin{array}{l}\text { Personal characteristics } \\
\text { and smoking habits }\end{array}$} & \multicolumn{2}{|c|}{ Potential DDls } & \multirow{3}{*}{$\mathbf{X}^{2}$} \\
\hline & \multirow{2}{*}{\begin{tabular}{|l|}
$\begin{array}{l}\text { Present } \\
(n=398)\end{array}$ \\
No. $(\%)$ \\
\end{tabular}} & \multirow{2}{*}{$\begin{array}{l}\text { Absent } \\
(n=352)\end{array}$} & \\
\hline & & & \\
\hline \multicolumn{4}{|c|}{ 1- Personal characteristics: } \\
\hline \multicolumn{4}{|l|}{ Age in years: } \\
\hline$<20$ & $32(24.6)$ & $98(75.4)$ & \multirow{5}{*}{$\begin{array}{l}100.1^{*} \\
p=0.000\end{array}$} \\
\hline $20-$ & $49(33.8)$ & $96(66.2)$ & \\
\hline $40-$ & $166(64.6)$ & $91(35.4)$ & \\
\hline $60-$ & $133(68.6)$ & $61(31.4)$ & \\
\hline $80+$ & $18(75.0)$ & $6(25.0)$ & \\
\hline Mean \pm SD (range) & \multicolumn{3}{|c|}{$44.46 \pm 21.29$ (9 months-99 years) } \\
\hline \multicolumn{4}{|l|}{ Sex: } \\
\hline Male & $226(55.0)$ & $185(45.0)$ & \multirow{2}{*}{$\begin{array}{l}1.3 \\
p=0.246\end{array}$} \\
\hline Female & $172(50.7)$ & $167(49.3)$ & \\
\hline \multicolumn{4}{|l|}{ Marital status: } \\
\hline Single & $34(27.2)$ & $91(72.8)$ & \multirow{4}{*}{$\begin{array}{l}52.6^{*} \\
p=0.000\end{array}$} \\
\hline Married & $298(62.2)$ & $181(37.8)$ & \\
\hline Widowed & $39(66.1)$ & $20(33.9)$ & \\
\hline Divorced & $12(48.0)$ & $13(52.0)$ & \\
\hline \multicolumn{4}{|l|}{ Education: } \\
\hline Illiterate & $158(64.8)$ & $86(35.2)$ & \multirow{6}{*}{$\begin{array}{l}35.9^{*} \\
p=0.000\end{array}$} \\
\hline Read and write & $92(62.2)$ & $56(37.8)$ & \\
\hline Primary or preparatory & $45(55.6)$ & $36(44.4)$ & \\
\hline Secondary & $51(42.1)$ & $70(57.9)$ & \\
\hline University & $45(37.8)$ & $74(62.2)$ & \\
\hline Post graduate & $0(0.0)$ & $1(100.0)$ & \\
\hline \multicolumn{4}{|l|}{ Occupation: } \\
\hline Don't work & $26(45.6)$ & $31(54.4)$ & \multirow{6}{*}{$\begin{array}{l}41.9^{*} \\
p=0.000\end{array}$} \\
\hline Housewife & $146(62.1)$ & $89(37.9)$ & \\
\hline Retired & $55(67.9)$ & $26(32.1)$ & \\
\hline Student & $21(26.3)$ & $59(73.8)$ & \\
\hline Skilled worker & $39(58.2)$ & $28(41.8)$ & \\
\hline Non skilled worker & $60(60.0)$ & $40(40.0)$ & \\
\hline \multicolumn{4}{|l|}{ 2- Smoking habits: } \\
\hline \multicolumn{4}{|l|}{ Smoking cigarettes } \\
\hline Yes & $179(63.0)$ & $105(37.0)$ & \multirow{2}{*}{$\begin{array}{l}11.1^{*} \\
p=0.001\end{array}$} \\
\hline No & $205(50.2)$ & $203(49.8)$ & \\
\hline \multicolumn{4}{|l|}{ Smoking shisha } \\
\hline Yes & $124(63.6)$ & $71(36.4)$ & \multirow{2}{*}{$\begin{array}{l}28.3^{*} \\
p=0.000\end{array}$} \\
\hline No & $260(52.3)$ & $237(47.7)$ & \\
\hline
\end{tabular}

*Significant $(p<0.05)$

Table 1: Distribution of potential DDIs among patients admitted to CCUs according to their personal characteristics and smoking habits (Alexandria, 2011).

The mean number of prescribed medications per prescription was $7 \pm 2$ medications (range, $4-15$ medications). It is clear from table 2 that as the number of medications prescribed increased, the prevalence of potential DDIs also increased. This association was statistically significant $\left(\mathrm{X}^{2}=101.2, p=0.000\right)$. The number of prescribing physicians per patient ranged from 1-14 physicians (mean=3 \pm 2 physicians). Unexpectedly, the prevalence of potential DDIs decreased as the number of prescribing physicians increased, except for patients who had 13 to 15 physicians, where all of them had potential DDIs. No statistically significant association was found. An almost equal prevalence of potential DDIs was found among both patients with and without hospital acquired infections, with a statistically insignificant difference. The proportion of potential DDIs was higher among patients who had co-morbid conditions, with a statistically significant difference $\left(\mathrm{X}^{2}=25.9, p=0.000\right)$. Finally, table 2 shows that patients with long term use of medications had a higher proportion of potential

DDIs. This association was statistically significant $\left(\mathrm{X}^{2}=19.6, p=0.000\right)$.

Table 3 shows the logistic regression analysis of the factors affecting the prevalence of potential DDIs among patients admitted to the CCUs as the dependent variable. Only two independent factors were found to be significantly affecting the prevalence of potential DDIs. The first factor was the patient's age $(\mathrm{OR}=1.023,95 \% \mathrm{CI}=1.012-1.034)$. The second was the number of prescribed drugs $(\mathrm{OR}=1.762,95 \% \mathrm{CI}=1.584$ 1.960). The model correctly classified $74.9 \%$ of cases.

\begin{tabular}{|c|c|c|c|}
\hline \multirow[t]{2}{*}{ Parameter } & \multicolumn{2}{|c|}{ Potential DDIs } & \multirow{3}{*}{$\mathbf{X}^{2}$} \\
\hline & \multirow{2}{*}{\begin{tabular}{|l}
$\begin{array}{l}\text { Present } \\
(\mathrm{n}=398)\end{array}$ \\
No. $(\%)$
\end{tabular}} & \multirow{2}{*}{\begin{tabular}{|l}
$\begin{array}{l}\text { Absent } \\
(n=352)\end{array}$ \\
No. $(\%)$
\end{tabular}} & \\
\hline & & & \\
\hline \multicolumn{4}{|c|}{ Length of stay in days: } \\
\hline \multicolumn{4}{|l|}{ Age in years: } \\
\hline$<5$ & $196(53.6)$ & $170(46.4)$ & \multirow{7}{*}{$\begin{array}{l}9.7 \\
p=0.139\end{array}$} \\
\hline 5- & $102(58.0)$ & $74(42.0)$ & \\
\hline $10-$ & $46(52.9)$ & $41(47.1)$ & \\
\hline $15-$ & $15(37.5)$ & $25(62.5)$ & \\
\hline $20-$ & $10(35.7)$ & $18(64.3)$ & \\
\hline $25-$ & $6(66.7)$ & $3(33.3)$ & \\
\hline $30+$ & $23(52.3)$ & $21(47.7)$ & \\
\hline Mean \pm SD (range) & \multicolumn{3}{|c|}{$9.02 \pm 12.7(1-125)$} \\
\hline \multicolumn{4}{|c|}{ Renal or hepatic impairment: } \\
\hline Yes & $285(55.9)$ & $225(44.1)$ & \multirow{2}{*}{$\begin{array}{l}5.1^{*} \\
p=0.024\end{array}$} \\
\hline No & $172(50.7)$ & $167(49.3)$ & \\
\hline \multicolumn{4}{|l|}{ APACHE II score: } \\
\hline$\leq 10$ & $109(47.2)$ & $122(52.8)$ & \multirow{5}{*}{$\begin{array}{l}13.4^{*} \\
p=0.010\end{array}$} \\
\hline $11-$ & $192(57.5)$ & $142(42.5)$ & \\
\hline 21- & $56(48.3)$ & $60(51.7)$ & \\
\hline $31-$ & $34(68.0)$ & $16(32.0)$ & \\
\hline $41-45$ & $7(36.8)$ & $12(63.2)$ & \\
\hline Mean \pm SD (range) & \multicolumn{2}{|c|}{$18 \pm 10(2-45)$} & \\
\hline \multicolumn{4}{|c|}{$\begin{array}{l}\text { Number of prescribed } \\
\text { medications/prescription: }\end{array}$} \\
\hline $4-6$ & $101(28.0)$ & $260(72.0)$ & \multirow{4}{*}{$\begin{array}{l}101.2^{*} \\
p=0.000\end{array}$} \\
\hline $7-9$ & $209(72.8)$ & $78(27.2)$ & \\
\hline $10-12$ & $79(84.9)$ & $14(15.1)$ & \\
\hline $13-15$ & $9(100.0)$ & $0(0.0)$ & \\
\hline Mean \pm SD (range) & $7 \pm 2(4-15)$ & $74(62.2)$ & \\
\hline \multicolumn{4}{|c|}{$\begin{array}{l}\text { Number of prescribing } \\
\text { physicians/patient: }\end{array}$} \\
\hline $4-6$ & $78(52.3)$ & $71(47.7)$ & \multirow{4}{*}{$\begin{array}{l}3.9 \\
p=0.268\end{array}$} \\
\hline $7-9$ & $18(46.2)$ & $21(53.8)$ & \\
\hline $10-12$ & $3(37.5)$ & $5(62.5)$ & \\
\hline $13-15$ & $3(100.0)$ & $0(0.0)$ & \\
\hline Mean \pm SD (range) & \multicolumn{2}{|l|}{$3 \pm 2(1-14)$} & \\
\hline \multicolumn{4}{|c|}{$\begin{array}{l}\text { Presence of hospital acquired } \\
\text { infection: }\end{array}$} \\
\hline Yes & $131(51.6)$ & $123(48.4)$ & \multirow{2}{*}{$\begin{array}{l}0.34 \\
p=0.558\end{array}$} \\
\hline No & $267(53.8)$ & $229(46.2)$ & \\
\hline \multicolumn{4}{|c|}{ Presence of co-morbidities: } \\
\hline Yes & $281(60.3)$ & $185(39.7)$ & \multirow{2}{*}{$\begin{array}{l}25.9^{*} \\
p=0.000\end{array}$} \\
\hline No & $117(41.2)$ & $167(58.8)$ & \\
\hline \multicolumn{4}{|c|}{ Long term use of medications: } \\
\hline Yes & $243(60.6)$ & $158(39.4)$ & \multirow{2}{*}{$\begin{array}{l}19.6^{*} \\
p=0.000\end{array}$} \\
\hline No & $155(44.4)$ & $194(55.6)$ & \\
\hline
\end{tabular}

*Significant $(p<0.05)$

APACHE, Acute Physiology and Chronic Health Evaluation

Table 2: Distribution of potential DDIs among patients admitted to CCUs according to certain parameters (Alexandria, 2011). 


\begin{tabular}{|l|l|l|l|l|}
\hline Independent variables & $\begin{array}{l}\text { Coefficient } \\
\mathrm{B}\end{array}$ & $\boldsymbol{p}$. value & Odds ratio & $\begin{array}{l}\text { 95\% Confidence } \\
\text { Interval }\end{array}$ \\
\hline Age & .022 & 0.000 & 1.023 & $1.012-1.034$ \\
\hline $\begin{array}{l}\text { Number of prescribed } \\
\text { drugs }\end{array}$ & .567 & 0.000 & 1.762 & $1.584-1.960$ \\
\hline Constant & -4.567 & & & \\
\hline
\end{tabular}

Sensitivity of the model was $74.9 \%$

Table 3: Logistic regression analysis of the factors affecting the prevalence of potential DDIs among patients admitted to CCUs (Alexandria, 2011).

\section{Discussion}

Drug interaction is a very important issue in drug therapy, especially in pediatric and geriatric patients. Patients admitted at the CCU are at higher risk for the development of DDIs. Patients in the CCU often are aged and have physiological alteration, summing up to unfavorable clinical conditions for drug metabolism such as shock, renal failure and hepatic disease [14]. The study highlighted a $53.07 \%$ prevalence of potential DDIs that would have resulted from the combinations of the prescribed drugs. This finding was comparable with those reported in other studies [5,27]. Higher rates were reported from Brazil in 2008 [14] and 2011 [4] and from Switzerland in 2010 [28], while lower rates were reported from Canada in 2007 [29] and Egypt in 2009 [18]. One important reason for discrepancies among studies is different classification and inclusion/exclusion of potential DDIs. Others reasons may include the decisions used to provide drug therapy, hospital pharmacists' work and the availability of electronic drug information system in the hospital.

The present study showed that interactions with significant levels 1.0 and 2.0 were among the most prevalent types, accounting for more than half of the potential DDIs observed. This means that in most cases the patient's life could be at risk and in such cases the physician and nursing staff should keep the patient under close observation. On the other hand, type 4.0 accounted for about one quarter of all potential DDIs, meaning that the drugs prescribed for patients will not cause any serious or fatal interactions [1]. Similar results were reported in other studies $[15,29]$. In contrast, other studies declared that the most prevalent type of interactions observed were types 4.0 and $5.0[14,30]$.

Most of the potential DDIs observed in the current study were of the delayed type, which could take up to several days or weeks to occur, needing no immediate concern or medical intervention [1]. Lower percentages of delayed onset potential DDIs, ranging from $48.7 \%$ to $61 \%$, were reported by many other studies $[5,14,15,27,30]$. On the other hand, higher percentages of delayed onset potential DDIs were reported by Iranmanesh et al., in 2012 (89.2\%) [31].

Considering the severity of interactions, the current study found that about one third of the potential DDIs observed were major interactions, and in such cases the patient's life could be threatened and immediate medical intervention is required [1]. Much lower rate was reported by Bertolia et al. (2010) [28]. About half of the potential DDIs in the present work had a moderate severity of action. In such case, patients should be kept under close observation to prevent any complications [1]. Other studies reported that nearly half of the interactions of moderate severity $[14,30]$. Higher percentages were found in several studies $[5,15,27,29,31]$.

Several studies reported that the most prevalent interactions were of possible and probable documentation, [5,14,15,29-31] which was in accordance with the current results. It should be noted that proper monitoring of patients, a reduction in the dosage regimen and increasing the dosing intervals could help to reduce risks of severe drug interactions which are well documented. Most of the observed potential DDIs counted for probable, suspected and possible documentation.

Regarding the top ten potential DDIs, interactions of oral anticoagulants (clopidorel) and low dose aspirin/statins/proton pump inhibitors (pantoprazole) ranked $1^{\text {st }}, 2^{\text {nd }}$ and $5^{\text {th }}$, respectively. This finding was comparable with that reported by Bertolia et al. (2010) [28]. Interactions of low dose aspirin and ACE inhibitors and the interaction of aspirin and corticosteroids ranked $3^{\text {rd }}$ and $6^{\text {th }}$ interactions, respectively. Similar findings were reported by Riechelmann et al. (2007) [29] and Hammes et al., (2009) [14]. The $7^{\text {th }}$ potential DDI resulted from the co-administration of furosemide with ramipril. Other studies reported comparable findings $[4,15]$. The $8^{\text {th }}$ potential interaction resulted from the concurrent use of aminoglycoside antibiotics as amikacin with cephalosporin antibiotics as cefoperazone. This finding was similar to that reported in another study [4].

The factors that had a significant association with the occurrence of DDIs in the present work included the patient's age, marital state, level of education, occupation, smoking cigarettes, smoking shisha, presence of renal or hepatic impairment, APACHE II score, number of prescribed medications per prescription, number of prescribing physicians per patient, presence of comorbidities and the long term use of medications. These findings were comparable with those reportd in several studies $[4-6,13,14,28,31]$.

Logistic regression analysis for the possible risk factors of DDIs among patients admitted to the CCUs in the present work showed that the age of patient and the number of prescribed drugs were the only significant factors. These findings were in accordance with other studies which showed that both variables were indeed two of the major, if not the most important, risk factors for DDIs [6,14,27-29]. Other risk factors for the occurrence of DDIs identified by other studies included sex [27] and length of hospital stay [4,6]. Although the current findings showed that DDIs were not preventable, awareness of the medical team on the prevalence, risk factors and mechanisms involved in the occurrence of potential DDIs can help in the reduction of the real occurrence of DDIs among hospitalized patients in general and the critically ill patients in specific.

In conclusion, critically ill patients are at risk of DDIs (53.07\%). Potential DDIs with a clinical value 1, possible documentation, delayed onset or moderate severity were the most frequently identified. Patients' age and the number of drugs prescribed were the independent risk factor for increase of this possibility. So, to avoid DDIs and improve the treatment of patients in the CCUs, continued education, computer system for prescriptions, pharmacotherapy monitoring of patients and the pharmacist participation in the multidisciplinary team are essential.

\section{References}

1. Tatro DS (2009) Drug interaction facts. St. Louis, MO: Wolters Kluwer Health, Inc.

2. Stockley IH (2005) editor. Stockley's Drug Interactions. 9th ed. London: Pharmaceutical Press

3. Bista D, Palaian S, Shankar PR, Prabhu MM, Paudel R, et al. (2007) Understanding the essentials of drug interactions: a potential need for safe and effective use of drugs. Kathmandu Univ Med J (KUMJ) 5: 421-430.

4. Reis AM, Cassiani SH (2011) Prevalence of potential drug interactions in patients in an intensive care unit of a university hospital in Brazil. Clinics (Sao Paulo) 66: 9-15.

5. Bista D, Saha A, Mishra P, Palaian S, Shankar PR (2009) Pattern of potentia drug-drug interactions in the intensive care unit of a teaching hospital in Nepal: a pilot study. JCDR 3: 1713. 
Citation: El Samia Mohamed SMA, Gad ZM, El-Nimr NA, Abdel Razek AAH (2013) Prevalence and Pattern of Potential Drug-Drug Interactions in the Critical Care Units of a Tertiary Hospital in Alexandria, Egypt. Adv Pharmacoepidemiol Drug Saf 2: 144. doi:10.4172/2167-1052.1000144

Page 6 of 6

6. Moura CS, Acurcio FA, Belo NO (2009) Drug-drug interactions associated with length of stay and cost of hospitalization. J Pharm Pharm Sci 12: 266-272.

7. Vonbach P (2009) Drug-drug interactions in the hospital. Basel: Südwestdeutscher Verlag Für Hochschulschriften AG.

8. Ernst FR, Grizzle AJ (2001) Drug-related morbidity and mortality: updating the cost-of-illness model. J Am Pharm Assoc (Wash) 41: 192-199.

9. Gennaro AR (2000) Remington: The science and practice of pharmacy. 20th ed. Philadelphia: Lippincott Williams \& Wilkins.

Adv Pharmacoepidemiol Drug

10. World Health Organization (2008) WHO Model F@sknulatotr-fespeva: WHO Press 634.

11. Lin $P$ (2003) Drug interactions and polypharmacy in the elderly. The Canadian Alzheimer disease review 10-4.

12. Helms RA (2006) Textbook of therapeutics: Drug and disease management 6th ed. Philadelphia, Pa: Lippincott Williams \& Wilkins.

13. Saokaew S, Maphanta S, Thangsomboon P (2009) Impact of pharmacist's interventions on cost of drug therapy in intensive care unit. Pharmacy Practice 7: 81-87.

14. Hammes JA, Pfuetzenreiter F, Silveira F, Koenig A, Westphal GA (2008) Potential drug interactions prevalence in intensive care units. Rev Bras TerIntensiva 20: 349-354.

15. Nazari MA, Moqhadam NK (2006) Evaluation of pharmacokinetic drug interactions in prescriptions of intensive care unit in a teaching hospital. Iran J Pharm Res 3: 215-218

16. Rafiei H, Arab M, Ranjbar H, Sepehri GR, Arab N, et al. (2012) The prevalence of potential drug interactions in Intensive Care Units. J Crit Care 4: 191-196.

17. Lima RE, De Bortoli Cassiani SH (2009) Potential drug interactions in intensive care patients at a teaching hospital. Rev Lat Am Enfermagem 17: 222-227.

18. Sabry NA, Farid SF, Abdel Aziz EO (2009) Role of the pharmacist in identification of medication related problems in the ICU: A preliminary screening study in an Egyptian teaching hospital. Aust J Basic appl sci 3: 995-1003
19. World Health Organization (2006) WHO Model Formulary. London: Roya Pharmaceutical Society of Great Britain 501

20. Tatro DS (2007) A to $Z$ drug facts. 8th ed. Lippincott Williams \& Wilkins, Facts \& Comparisons.

21. Skyscape.com [Internet]. Boston: Facts and comparisons; (C2010 [cited Jul 2011]. Skyscape.com, Inc.

22. Joint Formulary Committee. (2009) British national formulary. London: British Medical Association and Royal Pharmaceutical Society of Great Britain 978

23. MIMS [Internet]. USA: Drug interaction checker; @2013 [cited 2013 Jan 9]

24. Drugs.com [Internet]. New Zealand: Drug interactions checker. Wolters Kluwer Health, Physicians' Desk Reference, Cerner Multum and Thomson Micromedex; C2000-2010 [updated 2010 May 1; cited 2013 Jan 4].

25. Healthline [Internet]. Drug interaction checker. New York; @2005 - 2010 [updated 2010 May 1; cited 2012 Dec 12]

26. Medscape drug interaction checker [Internet]. New York: The American Society of Health-System Pharmacists; (C)1994-2010 [updated 2010 May 1; cited 2012 Nov 21].

27. Cruciol-Souza JM, Thomson JC (2006) A pharmacoepidemiologic study of drug interactions in a Brazilian teaching hospital. Clinics (Sao Paulo) 61: 515-520.

28. Bertoli R, Bissig M, Caronzolo D, Odorico M, Pons M, et al. (2010) Assessment of potential drug-drug interactions at hospital discharge. Swiss Med Wkly 140: w13043.

29. Riechelmann RP, Tannock IF, Wang L, Saad ED, Taback NA, et al. (2007) Potential drug interactions and duplicate prescriptions among cancer patients. J Natl Cancer Inst 99: 592-600.

30. Hajebi G, Mortazavi SA (2002) An investigation of drug interactions in hospita pharmacy prescriptions. Iran J Pharm Res 1: 15-19.

31. Iranmanesh S, Rafiei H, Aein F (2011) The study of potential drug-drug interactions among older patients admitted to the intensive care unit in Kerman, Iran. Middle East J Age Ageing 7: 37-41. 